\title{
RANCANG BANGUN PELAMPUNG PELACAK ARUS PERMUKAAN MENGGUNAKAN INSTRUMEN GPS
}

\author{
Design and Construction of The Buoy for Detecting Surface Current Movement Using GPS \\ Instrument
}

Oleh:

\author{
Deni Achmad Soeboer ${ }^{1 *}$, Budhi H. Iskandar ${ }^{2}$, Indra Jaya ${ }^{3}$, Mohammad Imron ${ }^{2}$ \\ ${ }^{1}$ Pascasarjana TPL-Dep PSP-FPIK-IPB \\ ${ }^{2}$ Departemen $P S P-F P I K-I P B$ \\ ${ }^{3}$ Departemen ITK-FPIK-IPB \\ *Korespondensi:denisoeboer@gmail.com
}

\begin{abstract}
ABSTRAK
Penelitian ini memanfaatkan keluaran dari instrumen GPS berupa track dan rute serta kecepatan. Instrumen GPS berada dalam satu pelampung yang dirancang khusus kedap air dan mempunyai semacam kelambu silinder di bawah permukaan airnya, kemudian dihanyutkan di perairan semi tertutup dengan jangka waktu tertentu. Data yang diperoleh dan tersimpan dalam memori GPS kemudian diplotkan menggunakan software yang tersedia untuk mendapatkan pola pergerakan arus permukaan di perairan. Pada saat yang bersamaan dilakukan juga pengukuran arus menggunakan alat pengukur arus (current meter) sebagai pembanding dari keluaran GPS yang dihasilkan dari pelampung pelacak pergerakkan arus permukaan. Penghanyutan pelampung terbagi menjadi 4 kwadran, hasil pengukuran kecepatan dan arah arus permukaan pada setiap kwadran, kemudian di regresikan dengan hasil dari keluaran GPS pelampung pelacak arus. Hasil regresi didapat persamaan y $=0,0618 x+0,1076$, dari persamaan tersebut dapat disimpulkan bahwa setiap kecepatan yang diproleh dari pelampung pelacak dikalikan 0,0618 untuk mmendapatkan kecepatan yang lebih mendekati sebenarnya.
\end{abstract}

Kata kunci: arus permukaan, current meter, GPS, rancang bangun pelampung

\begin{abstract}
This study utilizes the output of GPS instruments in the form of tracks and routes and speeds. GPS instruments are in one buoy designed specifically waterproof and have a kind of cylindrical mosquito net under the surface of the water, then washed away in semi-closed waters for a certain period of time. Data obtained and stored in GPS memory is then plotted using available software to obtain patterns of movement of surface currents in the waters. At the same time a measurement of current is also used using a current meter as a comparison of the GPS output produced from a tracking buoy to the movement of surface currents. Drifting buoy $s$ is divided into 4 quadrants, the results of measurements of the speed and direction of the surface currents in each quadrant, then regressed with the results of the GPS output of the current tracker buoy. The regression results obtained by the equation $y=0.0618 x+0.1076$, from the equation it can be concluded that each obtained speed from the tracking buoy is multiplied by 0.0618 to get a speed that is closer to the actual one.
\end{abstract}

Key words: current surface, current meter, design and construction of buoy, GPS 


\section{PENDAHULUAN}

Indonesia sebagai negara maritim dimana dua pertiga wilayahnya adalah perairan, maka sangatlah penting mengetahui karakteristik kondisi perairannya secara in situ guna pengembangan dan optimalisasi usaha perikanan dan kelautan. Karakteristik suatu wilayah perairan tersebut akan mudah diketahui dengan adanya data yang terbaru secara terus menerus (real time series data). Data tersebut meliputi data oseanografi baik fisik maupun kimia. Penelitian tentang oseanografi telah banyak dilakukan akan tetapi masih bersifat diskrit, snap shot, dan tidak sistematis (Hutabarat et al, 1985). Padahal kita ketahui bahwa laut sangatlah bersifat dinamis yang setiap saat mudah berubahubah. Kita sadari bahwa penelitian tentang oseanografi dengan perolehan data yang akurat diperlukan instrumen mutakhir dan mahal harganya serta biaya operasional tinggi (Burwell,1997). Sebagai contoh untuk mengukur arah dan kecepatan arus pada strata kedalaman menggunakan instrumen ADCP (Acoustic Doppler Current Profiler), alat ini sangat mahal dan di Indonesia baru beberapa instansi yang mempunyai instrumen seperti ini (Hutabarat et al,1985). Penelitian ini mencoba untuk mengetahui salah satu aspek oseanografi fisik yaitu pola pergerakan arus permukaan. Sebenarnya penelitian tentang pola pergerakan arus telah banyak dilakukan, akan tetapi dilakukan untuk lautan terbuka (samudera), seperti yang dilakukan oleh Boston University (1995-1996) di Samudera Hindia dengan melepas Bouy Diployment sebanyak 9 buah. Instrumen ini hanya dapat dipantau dari Boston (Amerika Serikat) karena instumen ini dilengkapi sistem transmiter dengan frekuensi tertentu untuk mengirim datanya melalui setelit (Borden, 1997).

Penelitian ini mencoba melacak pergerakan arus permukaan di perairan teluk (semi-close water) dengan menggunakan instrumen GPS. Seperti kita ketahui saat ini instrumen GPS sudah semakin banyak diaplikasikan untuk berbagai keperluan terutama informasi mengenai posisi di muka bumi (Abidin, 1995). Bidang kegiatan yang memerlukan informasi posisi tersebut seperti survei pemetaan darat dan laut, geodesi, transportasi dan navigasi. Pengukuran posisi menggunakan instrumen GPS dapat dilakukan secara terus menerus tanpa tergantung pada waktu dan cuaca, baik siang maupun malam, juga dalam kondisi yang buruk sekalipun seperti hujan ataupun kabut, sehingga dapat meningkatkan efisiensi dan fleksibilitas pelaksanaan pekerjaan survei dan pemetaan dengan tingkat ketelitian yang cukup baik (Abidin et al, 1995). Selain posisi (lintang dan bujur) data yang diperoleh dari pengopersian instrumen GPS antara lain adalah : waktu (tanggal dan jam), nomor satelit yang diterima, jumlah satelit, azimut dan ketinggian satelit, Horizontal Dilution of Precision, kecepatan, haluan, track, dan rute (Lindsay et al, 2002). Penelitian ini memanfaatkan keluaran dari instrumen GPS berupa track dan rute serta kecepatan. Instrumen GPS dalam satu pelampung yang dirancang khusus kedap air dan mempunyai semacam kelambu silinder di bawah permukaan airnya, kemudian dihanyutkan di perairan dengan jangka waktu tertentu. Data yang diperoleh dan tersimpan dalam memori GPS kemudian diplotkan menggunakan software yang tersedia untuk mendapatkan pola pergerakan arus permukaan di perairan. Perairan teluk yang akan memjadi tempat penelitian adalah Teluk Palabuhanratu karena perairan teluk Palabuhanratu merupakan salah satu pusat kegiatan perikanan di selatan Jawa Barat dan selain itu perairan teluk ini belum mempunyai data tentang pola pergerakan arus permukaan terkini dan terus menerus. Tujuan dari penelitian ini adalah merancang pelampung kedap air yang di dalamnya berisi instrumen GPS, plotkan keluaran instrumen berupa track/rute menggunakan software, mengetahui pola pergerakan arus dalam kurun waktu tertentu pada perairan teluk (semi-close water) Palabuhanratu.

\section{METODOLOGI PENELITIAN}

Penelitian ini dilaksanakan di Perairan Teluk Palabuhanratu, dan peralatan yang digunakan dalam penelitian ini seperti disajikan pada Tabel 1 berikut. 
Tabel 1 Daftar peralatan yang digunakan

\begin{tabular}{clll}
\hline No. & \multicolumn{1}{c}{ Alat } & Jumlah & \multicolumn{1}{c}{ Kegunaan } \\
\hline 1 & Buoy pelacak (Hasil rancang bangun) & 1 unit & $\begin{array}{l}\text { Melacak pergerakan arus di dalam } \\
\text { terdapat instrumen GPS (Plus III) }\end{array}$ \\
& Instrumen GPS (Garmin Tipe Plus III & 2 unit & Penerima data posisi, trtack dan rute \\
2 & dan Etrex) & 1 unit & Menyimpan dan memproses data \\
3 & Notebook (laptop) & 1 unit & Untuk pelepasan buoy dan verifikasi \\
4 & Perahu nelayan & 1 unit & Untuk memantau buoy \\
5 & Teropong/binocular & 1 unit & Untuk verifikasi instrumen GPS buoy \\
\hline
\end{tabular}

Penelitian ini menggunakan metode pengamatan langsung di lapangan, penelitian ini dilakukan di perairan Teluk Palabuhanratu. Kegiatan penelitian ini melalui tahapan sebagai berikut : Tahap rancang bangun pelampung pelacak, Tahap uji coba laboratorium, Tahap pelepasan instrumen di lapangan, Tahap verifikasi alat, Tahap Pengolahan data.

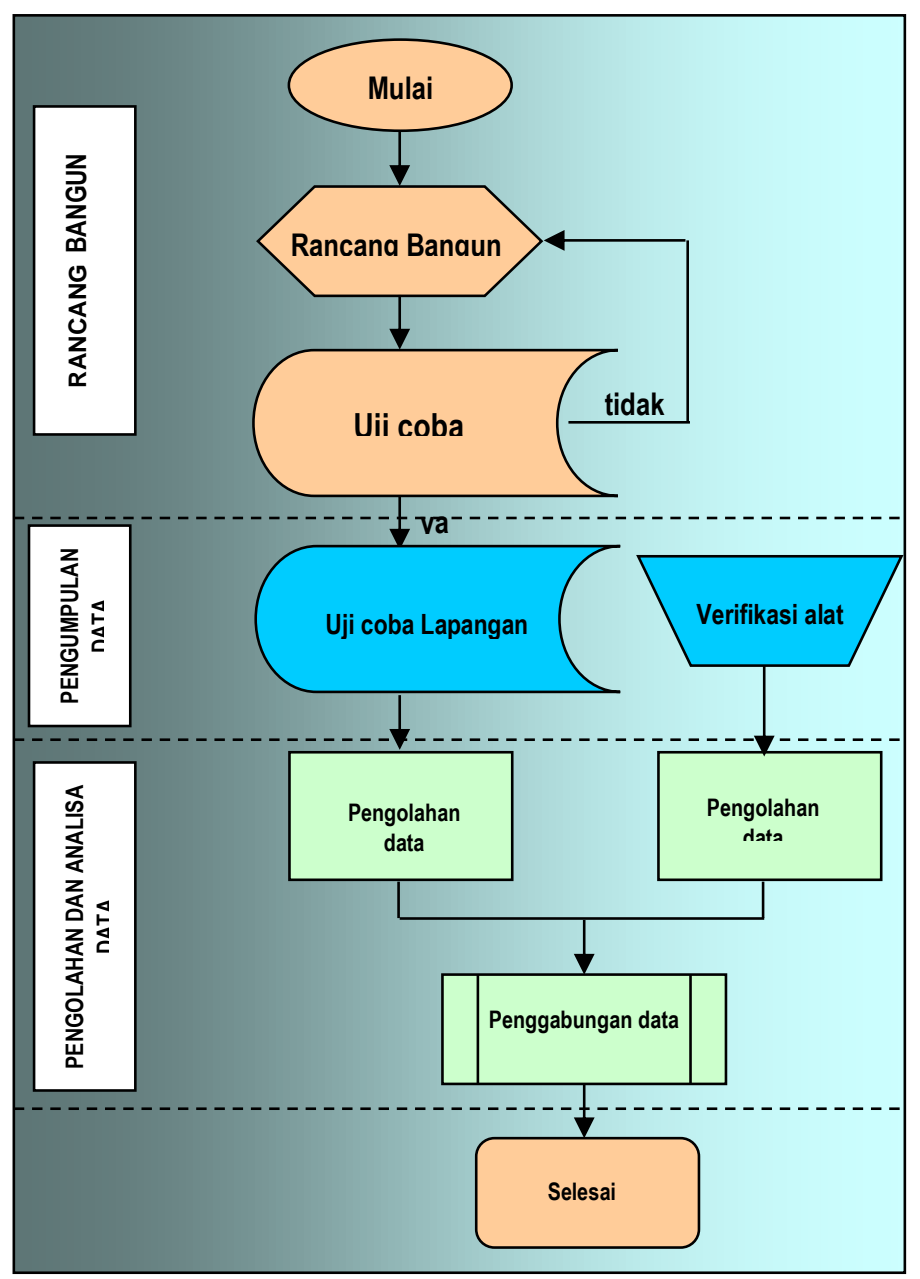

Gambar 1 Desain Penelitian

Tahap rancang bangun alat dilakukan di Laboratorium Instrumen dan Akustik Kelautan Dep. ITK dengan menggunakan material yang mudah didapat dipasaran, pada tahap ini terdapat dua bagian utama yaitu: 
- bagian di atas air berupa pelampung/buoy platik $(\varnothing 30 \mathrm{~cm})$ yang dipotong bagian atasnya dan sambung kembali menggunakan mur baut akan tetapi tetap kedap air, bagian atas pelapung/ buoy disambung dengan tiang antena berupa pipa PVC 3/4" setinggi $50 \mathrm{~cm}$.

- bagian bawah air berupa kelambu selinder $\varnothing 60 \mathrm{~cm}$ setinggi $220 \mathrm{~cm}$, rangka selinder terbuat dari besi beton $\varnothing 6 \mathrm{~mm}$, kelambunya terbuat dari bahan waring dan pemberat batu seberat $1,5 \mathrm{~kg}$.

Tahap uji coba di laboratorium selain uji coba penampilan buoy di atas air juga dilakukan uji kerja GPS setelah terpasang di dalam buoy, tahap ini dilakukan pada laboratorium instrumen dan akustik kelautan Dep. ITK.

Tahap pelepasan instrumen didahului dengan uji coba lapangan sekaligus pengambilan data, pada tahap ini melihat penampilan buoy pada kondisi sebenarnya dan selanjutnya dilakukan pengambilan data serta verifikasi instrumen. Pada tahap pengolahan data melakukan pengolahan data dari buoy dan data hasil verifikasi selanjutnya dilakukan penggabungan hasil olah dari kedua data tersebut.

Metode pengumpulan data utama dengan melakukan pengamatan langsung di lapangan yaitu berupa data kinerja buoy pelacak dan data verifikasi. Untuk mempermudah pengamatan, dan pengumpulan data maka perairan Teluk Palabuhanratu dibagi menjadi 4 kwadran (I, II, III, IV) seperti diperlihatkan pada Gambar 2.

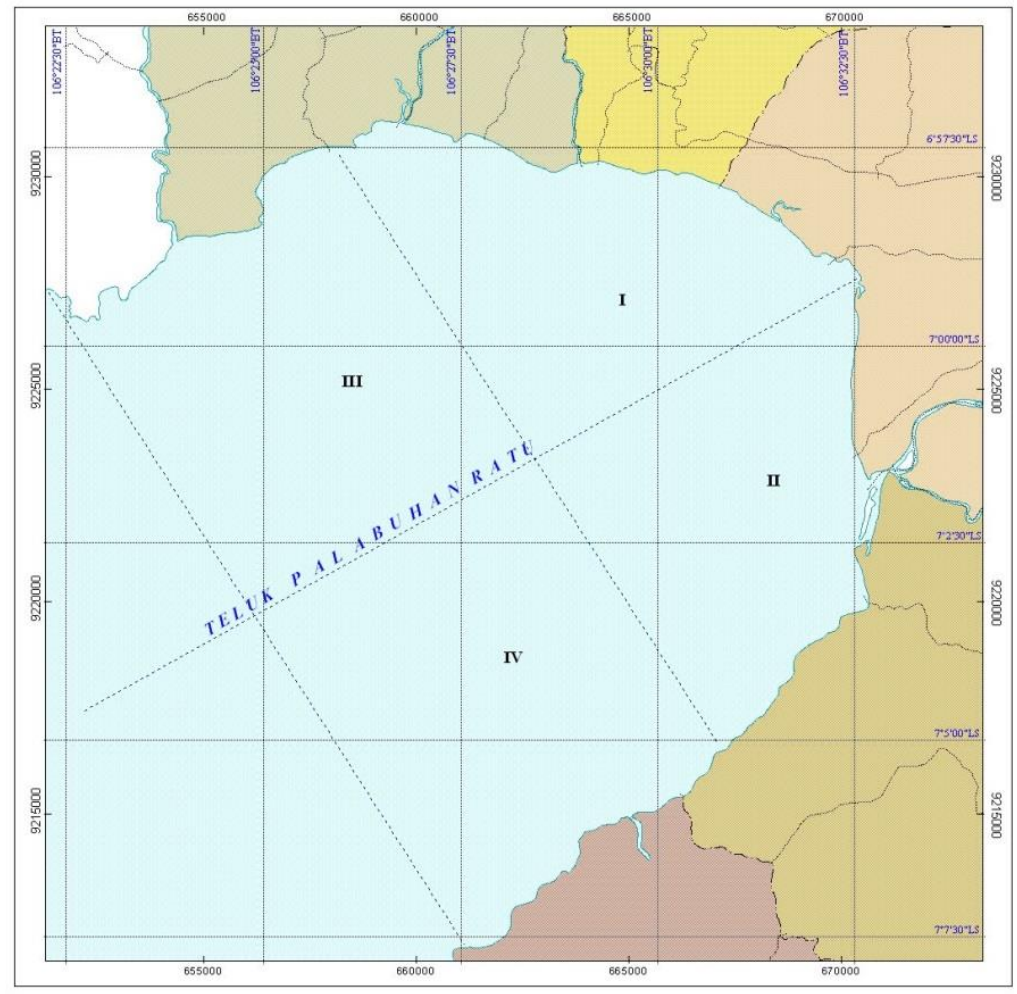

Gambar 2 Pembagian Kwadran Perairan Teluk Palabuhanratu

Pada setiap kwadran dilakukan pelepasan instrumen buoy pelacak arus permukaan dengan instrumen GPS selama 6 jam, pada waktu bersamaan dilakukan juga pengukuran arus permukaan di beberapa titik stasiun yang telah ditentukan menggunakan current meter untuk keperluan verifikasi data.

(1) Pelepasan buoy di perairan

Pelepasan Instrumen GPS buoy dilakukan sehari pada setiap kwadran dengan lama penghanyutan 6 jam, hal ini dilakukan karena buoy pelacak yang dibuat hanya satu. Lama 
penghanyutan 6 jam karena keterbatan catudaya yang hanya mengandalkan pada baterai yang tersedia pada GPS dan mengantisipasi kapasitas memori dalam GPS, serta selama itu diharapkan sudah dapat meliputi pengaruh waktu pasang dan surut.

(2) Kegiatan verifikasi

Kegiatan ini dilakukan dari atas perahu mengikuti hanyutnya buoy pelacak, untuk mengambil data kecepatan dan arah arus permukaan menggunakan current meter pada titik-titik stasiun yang terdekat dengan hanyutnya buoy.

Gambar 3 menampilkan bagan alir proses pengolahan data buoy pelacak arus permukaan menggunakan instrumen GPS :

Pengolahan data pola arus dengan cara mentransfer data track dari GPS menggunakan komputer dan software MapSource dan selanjutnya menggunakan software ArcView untuk memperhalus tampilan.

\section{Analisis data kecepatan arus}

Kecepatan dan arus dianalisa menggunakan perhitungan regresi sederhana dari masingmasing data GPS buoy pelacak dan hasil pengukuran langsung menggunakan current meter.

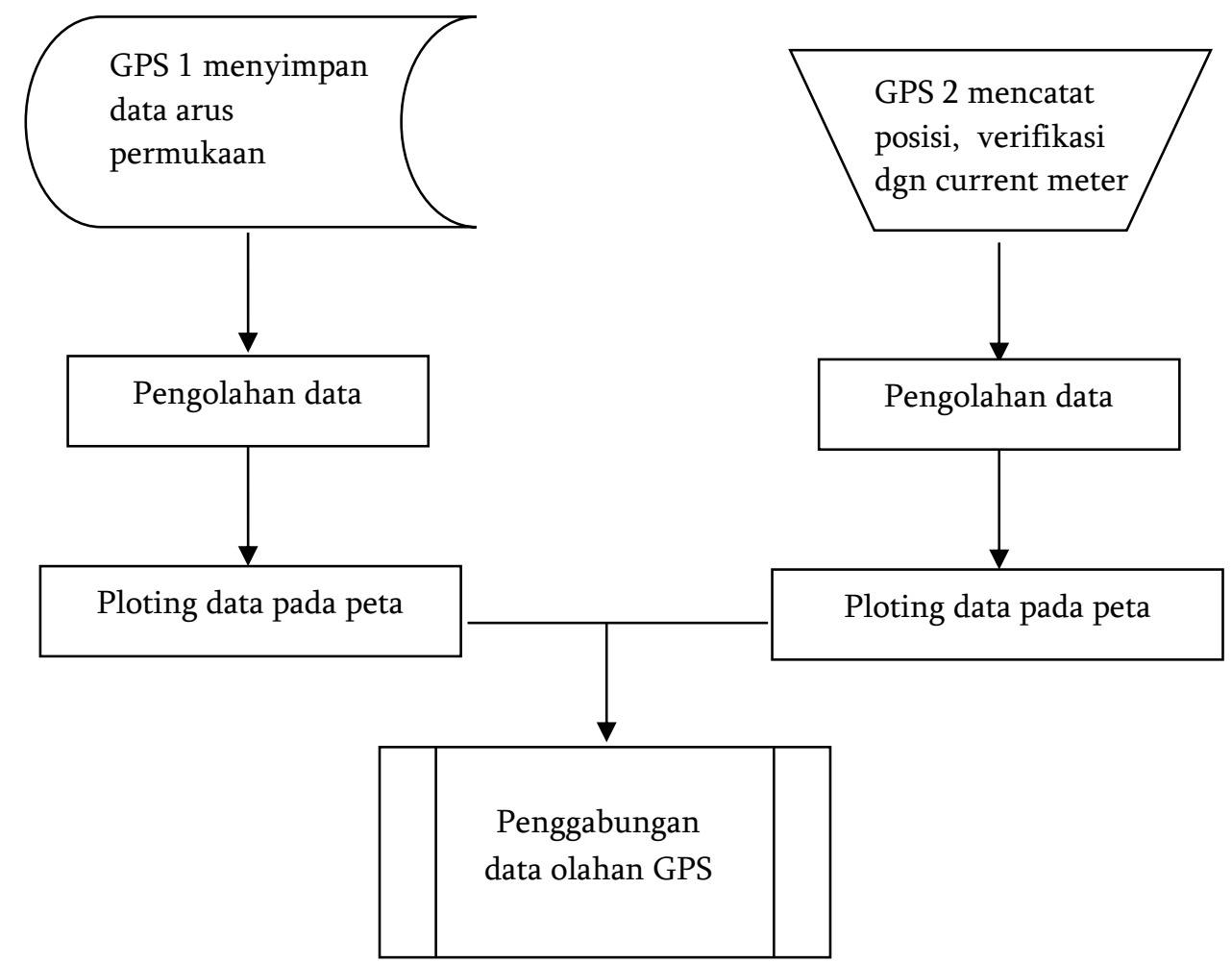

Gambar 3 Diagram Alir Proses Pengolahan data

\section{HASIL DAN PEMBAHASAN}

\section{Rancang Bangun Alat}

Penelitian ini menghasilkan instrumen buoy pelacak pergerakan arus permukaan laut yang sederhana dan biaya pembuatannya relatif murah dengan bagian dan ukuran seperti yang diperlihat pada Tabel 2, dan konstruksi dibuat seperti yang pernah dilakukan oleh Sybrandy et al, 1991. 
Tabel 2 Bagian-bagian Instrumen buoy pelacak arus

\begin{tabular}{|c|c|c|c|c|}
\hline No & Bagian & Material & Ukuran & Keterangan \\
\hline 1 & $\begin{array}{l}\text { Pelampung Utama } \\
\text { (Gambar 19) }\end{array}$ & Fibreglass & $\begin{array}{l}\text { Ǿ } 30 \mathrm{~cm} \text {, } \\
\text { Daya apung } \\
=14,5 \mathrm{kgf}\end{array}$ & $\begin{array}{l}\text { Pelampung ini biasa digunakan untuk } \\
\text { pelmpung alat tangkap long line, } \\
\text { bagian atasnya disayat dan dibentuk } \\
\text { segi-8 pada kedua bidang sayatan untuk } \\
\text { disambung kembali menggunakan mur } \\
\text { baut } 3 / 8 \text { " sebanyak } 8 \text { buah. Puncaknya } \\
\text { diberi lubang untuk tiang antenna GPS. }\end{array}$ \\
\hline 2 & Tiang antena & PVC & $\begin{array}{l}\emptyset^{3} / 4 ”, \text { tinggi } \\
50 \mathrm{~cm}\end{array}$ & $\begin{array}{l}\text { Ujung atas (top) diberi sok drat luar } 3 / 4 \text { " } \\
\text { untuk peletakan antena, ujung bawah } \\
\text { disambungkan dengan pelampung } \\
\text { utama. }\end{array}$ \\
\hline 3 & Antena & & $\begin{array}{l}\text { Ǿ3/4”, tinggi } \\
20 \mathrm{~cm}\end{array}$ & $\begin{array}{l}\text { Menggunakan Antena Garmin Type } \\
\text { GA 29, kabel dan soket antena } \\
\text { dimasukkan melalui rongga tiang PVC } \\
\text { hingga ke rongga pelampung utama }\end{array}$ \\
\hline 4 & Instrumen GPS & & $\begin{array}{l}15,6 \times 5,1 \times 1,23 \\
\mathrm{~cm}\end{array}$ & $\begin{array}{l}\text { GPS yang digunakan adalah Garmin } \\
\text { Type GPS III plus }\end{array}$ \\
\hline 5 & $\begin{array}{l}\text { Kelambu silinder : } \\
\text { - Rangka }\end{array}$ & $\begin{array}{l}\text { Besi beton } \\
\text { Waring }\end{array}$ & 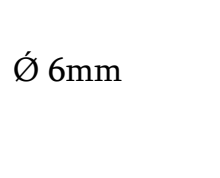 & $\begin{array}{l}\text { Dibuat, melingkar dengan } \varnothing 60 \mathrm{~cm} \\
\text { sebanyak } 3 \text { buah dan dilapisi selang } \\
\text { platik, }\end{array}$ \\
\hline & - Kelambu & & $\begin{array}{l}\text { MS 0,5 cm, Ǿ } \\
60 \mathrm{~cm} \text {, tinggi } \\
220 \mathrm{~cm}\end{array}$ & $\begin{array}{l}\text { Dibuat melingkar dengan, rangka } \\
\text { dipasang pada bagian atas, tengah dan } \\
\text { bawah. } \\
\text { Pada bagian atas rangka beri tali timba } \\
3 \text { penjuru setinggi } 50 \mathrm{~cm}\end{array}$ \\
\hline 6 & Tali sambung & Kuralon & $\begin{array}{l}\text { Ǿ } 4 \mathrm{~mm} \text {, } \\
\text { panjang } 1 \mathrm{~m}\end{array}$ & $\begin{array}{l}\text { Tali kuralon untuk menyambungkan } \\
\text { antara pelampung utama dan kelambu, } \\
\text { tali ini diberi kili-kili agar tidak melilit }\end{array}$ \\
\hline 7 & Pemberat & Semen cor & Berat $1 \mathrm{~kg}$ & $\begin{array}{l}\text { Pemberat berfungsi sebagai } \\
\text { penyeimbang tegaknya pelampung } \\
\text { utama dan diikatkan pada pelampung } \\
\text { utama bagian bawah }\end{array}$ \\
\hline
\end{tabular}




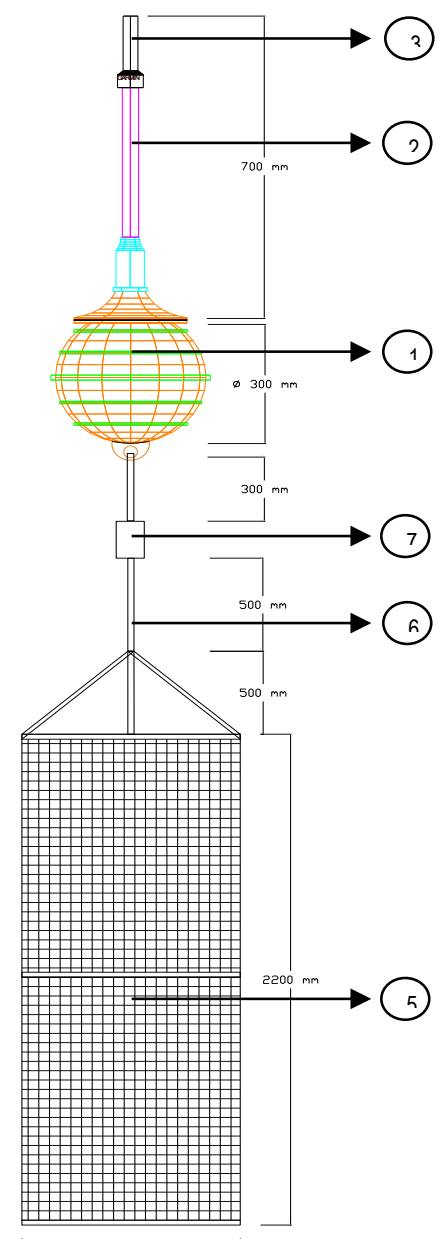

Gambar 4. Rancangan GPS Buoy

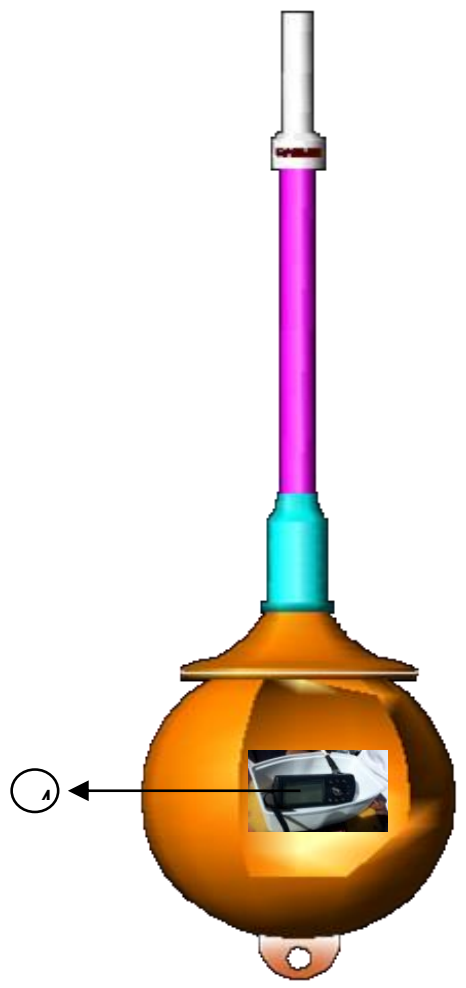

Gambar 5. Pelampung Utama

\section{Pengoperasian Instrumen}

Langkah-langkah dalam mengoperasikan instrumen ini adalah sebagai berikut :

(a) Rangkai semua bagian instrumen ini mulai dari kelambu dan pelampung utama, pastikan semua terikat sempurna;

(b) Buka bagian atas pelampung utama, GPS dalam keadaan "on" dan hubungkan antena nya, pastikan fungsi track log pada GPS "on" dan bekerja dengan baik tempatkan dalam kotak kemudian masukan kedalam pelampung utama, tutup pelampung utama dan kencangkan semua baut agar kedap air;

(c) Turunkan ke laut berturut-turut kelambu diukuti pelampung utama, biarkan hanyut;

(d) Setelah beberapa jam hanyut, angkat pelampung utama kemudian buka, pastikan GPS masih dalam keadaan "on" dan lihat track tergambar pada GPS selanjutnya dimatikan ('Off')

\section{Hasil Penelitian}

Data track arus yang terekam dalam instrumen GPS dari ke empat kwadran kemudian ditransfer ke komputer menggunakan program MapSource. Hasil transfer dari instrumen GPS ke komputer menggunakan program MapSource adalah sebagai berikut : 


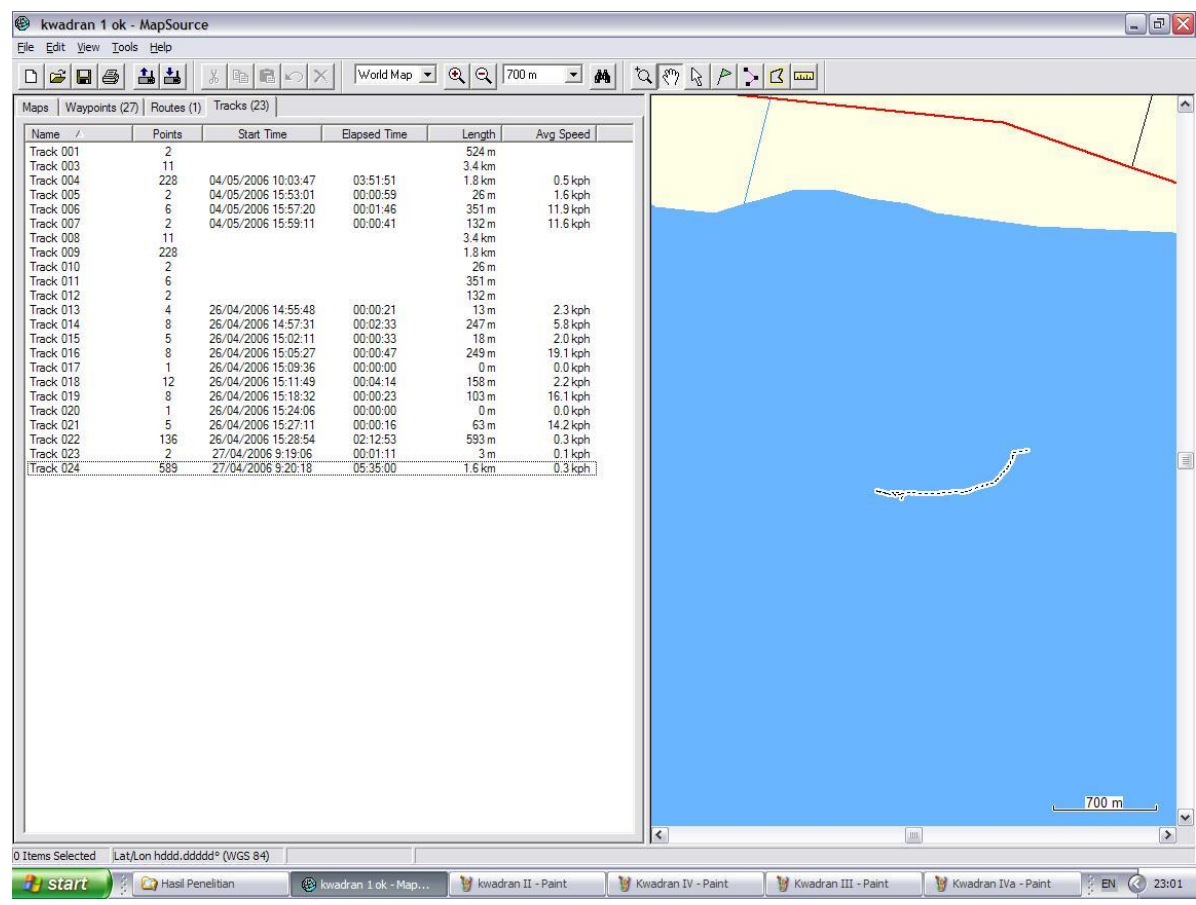

Gambar 6 Track arus permukaan pada Kwadran 1

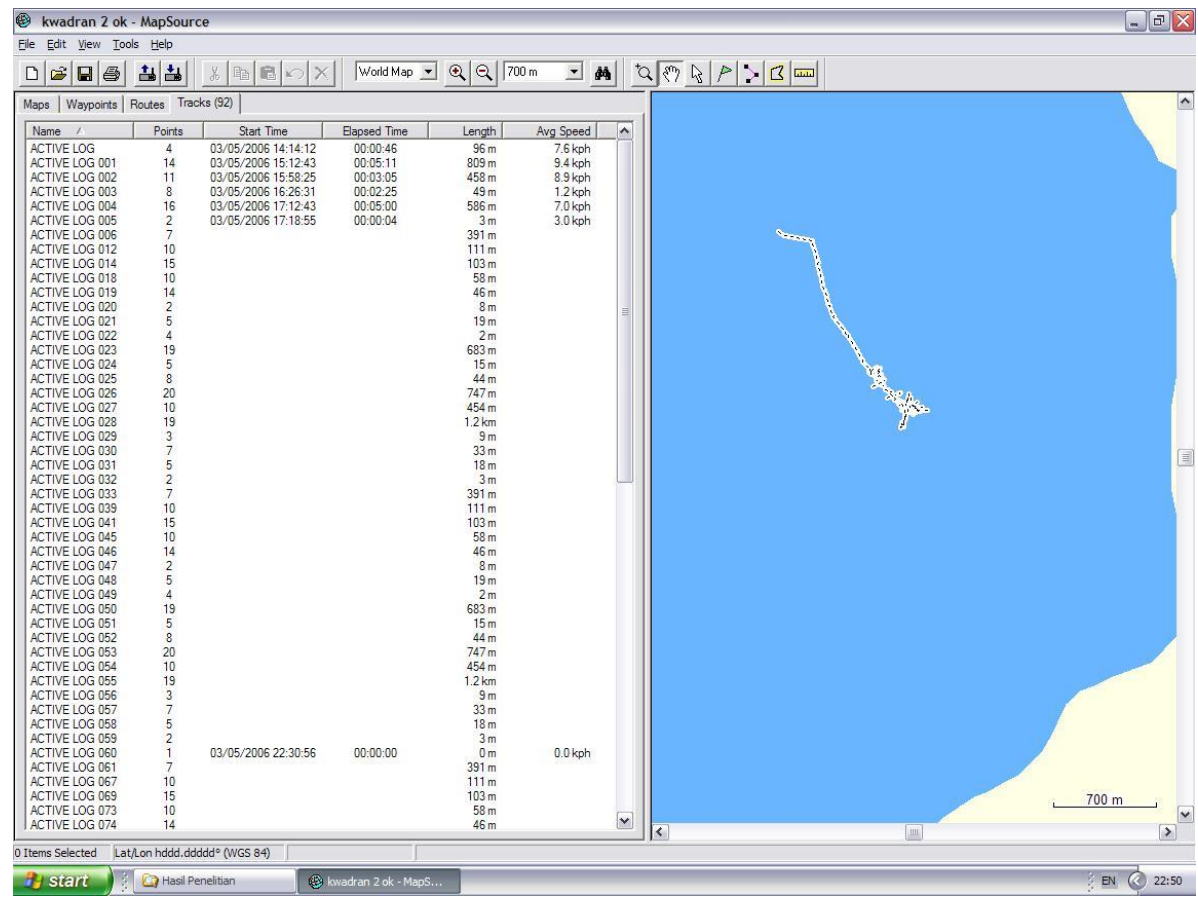

Gambar 7 Track arus permukaan pada Kwadran 2 


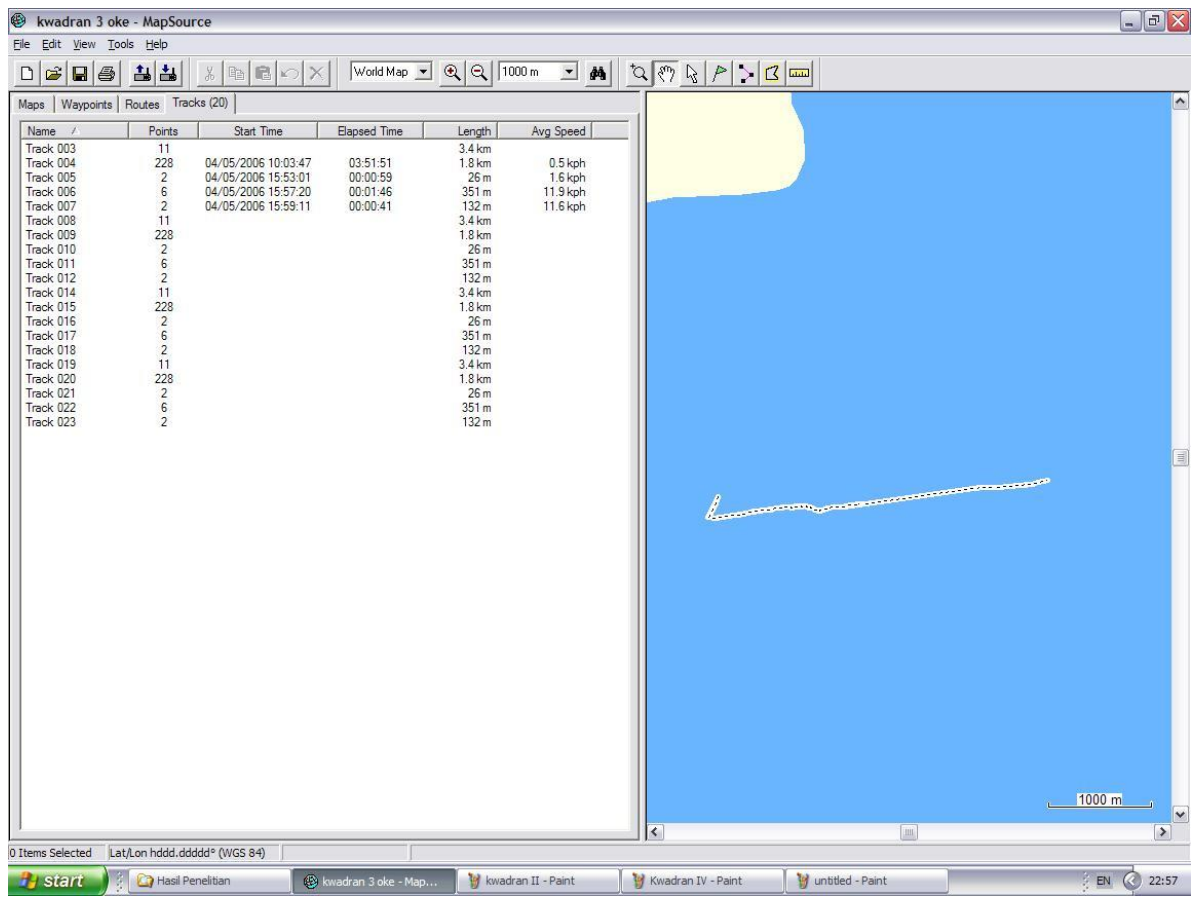

Gambar 8 Track arus permukaan pada Kwadran 3

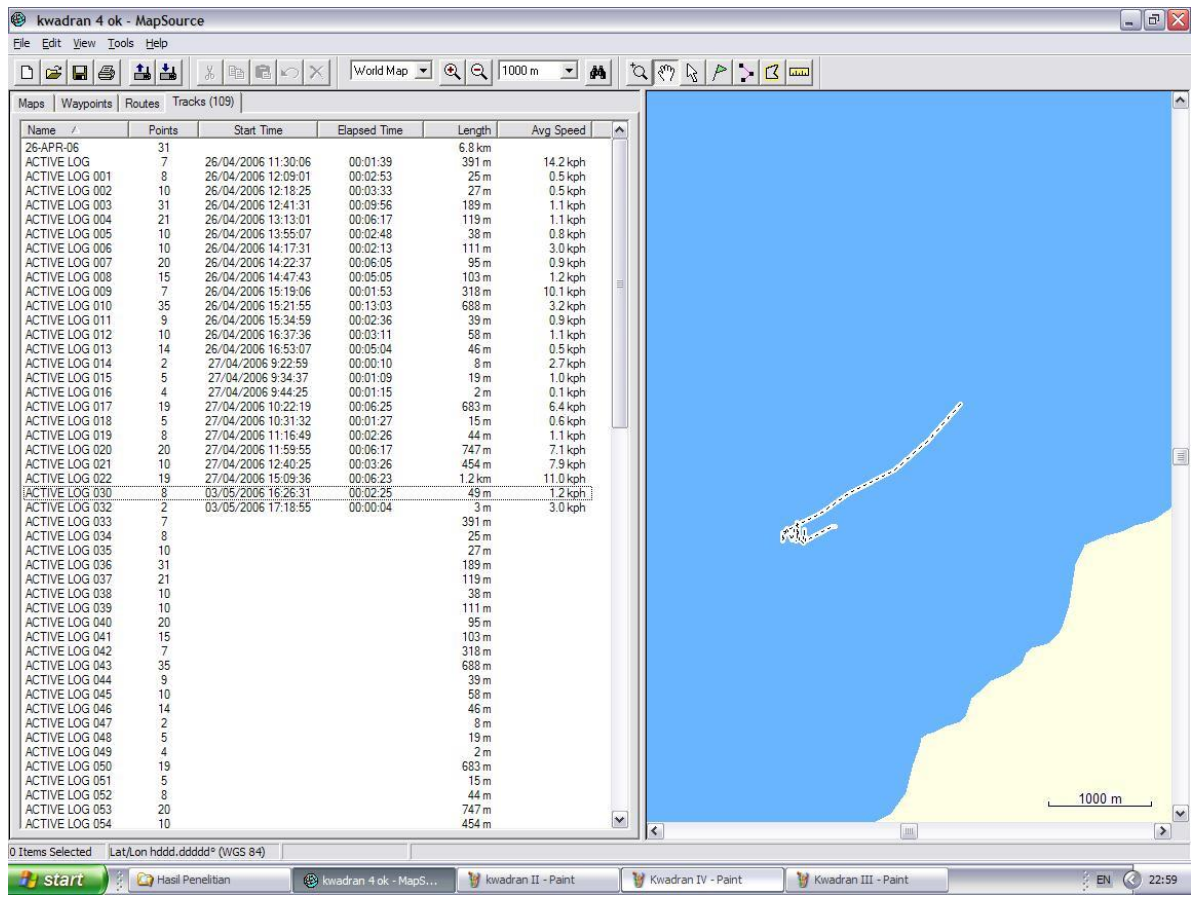

Gambar 9 Track arus permukaan pada Kwadran 4

Pada saat yang bersamaan dengan penghanyutan instrumen GPS buoy, dilakukan pengukuran arus menggunakan current meter pada titik-titik stasiun yang ditentukan sebagai verifikasi dan penentuan posisi-posisi stasiun dilakukan menggunakan instrumen GPS ke-2. Hasil pengukuran kecepatan dan arah arus verifikasi menggunakan current meter pada masing-masing kwadran ditampilkan pada Tabel 4-2 berikut ini : 
Tabel 3 Pengukuran Kecepatan dan Arah arus pada kwadran 1

\begin{tabular}{ccccc}
\hline Kwadran 1 & Ulangan & Kecepatan $(\mathrm{m} / \mathrm{det})$ & Rataan $(\mathrm{m} / \mathrm{det})$ & Arah $\left(^{0}\right)$ \\
\hline \multirow{3}{*}{ Stasiun 1 } & 1 & 0.070 & & \\
& 2 & 0.069 & 0.073 & $165^{0}$ \\
\multirow{3}{*}{ Stasiun 2 } & 3 & 0.079 & & \\
& 1 & 0.087 & 0.106 & $150^{0}$ \\
Stasiun 3 & 3 & 0.073 & & \\
& 1 & 0.159 & 0.170 & $150^{\circ}$ \\
\hline
\end{tabular}

Tabel 4 Pengukuran kecepatan dan arah arus pada kwadran 2

\begin{tabular}{|c|c|c|c|c|}
\hline Kwadran 2 & Ulangan & $\operatorname{Kecepatan}(\mathrm{m} / \mathrm{det})$ & Rataan (m/det) & Arah $\left(^{0}\right)$ \\
\hline \multirow{4}{*}{ Stasiun 4} & 1 & 0.070 & & \\
\hline & 2 & 0.069 & 0.073 & $165^{\circ}$ \\
\hline & 3 & 0.079 & & \\
\hline & 1 & 0.087 & & \\
\hline \multirow[t]{3}{*}{ Stasiun 5} & 2 & 0.073 & 0.106 & $150^{\circ}$ \\
\hline & 3 & 0.159 & & \\
\hline & 1 & 0.164 & & \\
\hline \multirow[t]{3}{*}{ Stasiun 6} & 2 & 0.169 & 0.170 & $150^{\circ}$ \\
\hline & 3 & 0.200 & & \\
\hline & 1 & 0.120 & & \\
\hline \multirow[t]{3}{*}{ Stasiun 7} & 2 & 0.152 & 0.121 & $170^{\circ}$ \\
\hline & 3 & 0.091 & & \\
\hline & 1 & 0.115 & & \\
\hline \multirow[t]{3}{*}{ Stasiun 8} & 2 & 0.161 & 0.143 & $165^{0}$ \\
\hline & 3 & 0.154 & & \\
\hline & 1 & 0.156 & & \\
\hline \multirow[t]{3}{*}{ Stasiun 9} & 2 & 0.200 & 0.179 & $165^{0}$ \\
\hline & 3 & 0.182 & & \\
\hline & 1 & 0.105 & & \\
\hline \multirow[t]{2}{*}{ Stasiun 10} & 2 & 0.179 & 0.146 & $175^{0}$ \\
\hline & 3 & 0.154 & & \\
\hline
\end{tabular}


Tabel 5 Pengukuran Kecepatan dan arah arus pada kwadran 3

\begin{tabular}{|c|c|c|c|c|}
\hline Kwadran 3 & Ulangan & Kecepatan (m/det) & Rataan (m/det) & Arah $\left(^{0}\right)$ \\
\hline \multirow{3}{*}{ Stasiun 11} & 1 & 0,110 & \multirow{3}{*}{0,116} & \multirow{3}{*}{80} \\
\hline & 2 & 0,115 & & \\
\hline & 3 & 0,123 & & \\
\hline \multirow{3}{*}{ Stasiun 12} & 1 & 0,105 & \multirow{3}{*}{0,102} & \multirow{3}{*}{80} \\
\hline & 2 & 0,111 & & \\
\hline & 3 & 0,091 & & \\
\hline \multirow{3}{*}{ Stasiun 13} & 1 & 0,167 & \multirow{3}{*}{0,160} & \multirow{3}{*}{75} \\
\hline & 2 & 0,159 & & \\
\hline & 3 & 0,154 & & \\
\hline \multirow{3}{*}{ Stasiun 14} & 1 & 0,149 & \multirow{3}{*}{0,142} & \multirow{3}{*}{80} \\
\hline & 2 & 0,133 & & \\
\hline & 3 & 0,143 & & \\
\hline \multirow{3}{*}{ Stasiun 15} & 1 & 0,154 & \multirow{3}{*}{0,158} & \multirow{3}{*}{75} \\
\hline & 2 & 0,159 & & \\
\hline & 3 & 0,161 & & \\
\hline \multirow{3}{*}{ Stasiun 16} & 1 & 0,147 & \multirow{3}{*}{0,145} & \multirow{3}{*}{70} \\
\hline & 2 & 0,143 & & \\
\hline & 3 & 0,145 & & \\
\hline \multirow{3}{*}{ Stasiun 17} & 1 & 0,156 & & \multirow{3}{*}{75} \\
\hline & 2 & 0,147 & 0,148 & \\
\hline & 3 & 0,141 & & \\
\hline
\end{tabular}

Tabel 6 Pengukuran Kecepatan dan arah arus pada kwadran 4

\begin{tabular}{ccccc}
\hline Kwadran 4 & Ulangan & Kecepatan $(\mathrm{m} / \mathrm{det})$ & Rataan $(\mathrm{m} / \mathrm{det})$ & Arah $\left(^{0}\right)$ \\
\hline \multirow{3}{*}{ Stasiun 18} & 1 & 0,118 & & \\
& 2 & 0,111 & 0,110 & \\
Stasiun 19 & 3 & 0,100 & & \\
& 1 & 0,128 & 0,135 & \\
Stasiun 20 & 3 & 0,143 & & \\
& 1 & 0,133 & & \\
& 2 & 0,154 & 0,142 & \\
Stasiun 21 & 3 & 0,125 & & \\
& 1 & 0,147 & & \\
& 2 & 0,103 & 0,110 & \\
Stasiun 22 & 3 & 0,109 & & \\
& 1 & 0,118 & & \\
& 2 & 0,118 & 0,112 & \\
Stasiun 23 & 3 & 0,123 & & \\
& 1 & 0,110 & & \\
& 2 & 0,105 & 0,110 & \\
\hline
\end{tabular}

\section{Pengolahan Track arus permukaan dan stasiun verifikasi}

Track arus yang dihasilkan oleh buoy pelacak dan stasiun-stasiun verifikasi dapat diplotkan secara bersamaan serta tampilan track arus buoy pelacak dapat ditambahkan arahnya, maka kedua 
data tersebut diolah menggunakan program Arcview. Hasil pengolahan menggunakan program tersebut pada setiap kwadran ditampilkan berturut-turut pada gambar berikut ini. Ke-4 kwadran bila ditampilkan secara bersamaan akan lebih memperjelas gambaran pola arus di Teluk Palabuhanratu seperti ditampilkan pada gambar berikut ini :

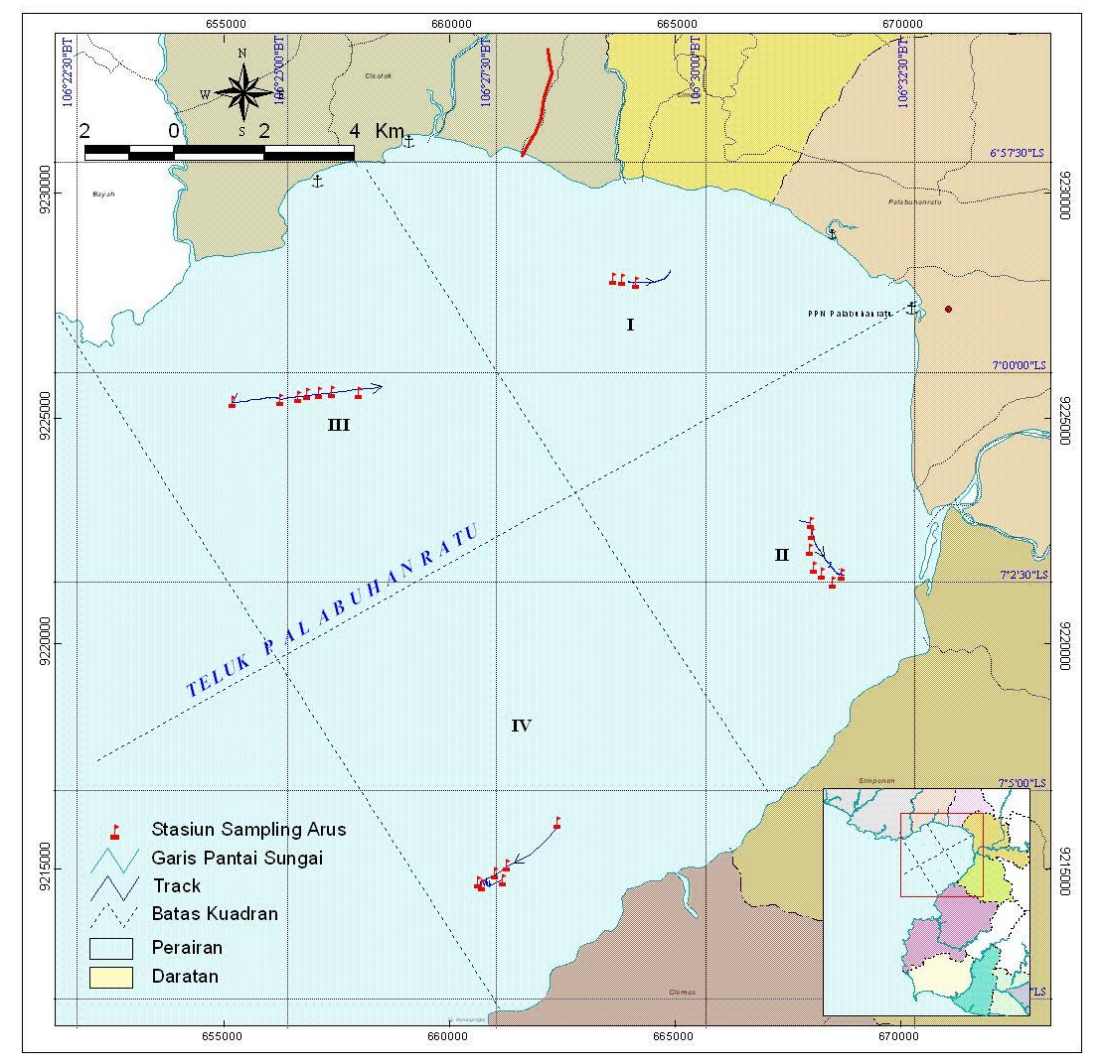

Gambar 10 Gambaran pola arus di Teluk Palabuhanratu

\section{Analisis Kecepatan arus}

Kecepatan arus yang dihasilkan oleh buoy pelacak mempunyai perbedaan bila dibandingkan dengan hasil pengukuran menggunakan current meter sebagai alat standar. Pengukuran dilakukan pada stasiun-stasiun yang berdekatan dengan track buoy pelacak. Posisi pada track yang diambil sebagai contoh disajikan pada Tabel 7 sampai dengan Tabel 10.

Kecepatan arus yang diperoleh baik dari buoy pelacak maupun pengukuran langsung menggunakan current meter terdapat perbedaan, sehingga untuk mendapatkan kecepatan arus yang lebih mendekati dan sesuai alat standar dapat dilakukan dengan meregresikan kedua nilai kecepatan tersebut. Hasil regresi sederhana kedua kecepatan tersebut diperlihat pada Gambar 11.

Tabel 7 Kecepatan arus buoy pelacak pada posisi yang berdekatan dengan stasiun-stasiun di kwadran 1

\begin{tabular}{ccc}
\hline Kwadran 1 & Kecepatan (m/det) & Arah $\left(^{\circ}\right)$ \\
\hline Stasiun 1 & 0,083 & $165^{0}$ \\
Stasiun 2 & 0,083 & $150^{\circ}$ \\
Stasiun 3 & 0,028 & $150^{\circ}$ \\
\hline
\end{tabular}


Tabel 8 Kecepatan arus buoy pelacak pada posisi yang berdekatan dengan stasiun-stasiun di kwadran 2

\begin{tabular}{ccc}
\hline Kwadran 2 & Kecepatan $(\mathrm{m} / \mathrm{det})$ & Arah $\left(^{\circ}\right)$ \\
\hline Stasiun 4 & 0,139 & $165^{0}$ \\
Stasiun 5 & 0,139 & $150^{\circ}$ \\
Stasiun 6 & 0,222 & $150^{0}$ \\
Stasiun 7 & 0,139 & $170^{\circ}$ \\
Stasiun 8 & 0,139 & $165^{0}$ \\
Stasiun 9 & 0,250 & $165^{0}$ \\
Stasiun 10 & 0,222 & $175^{0}$ \\
\hline
\end{tabular}

Tabel 9 Kecepatan arus buoy pelacak pada posisi yang berdekatan dengan stasiun-stasiun di kwadran 3

\begin{tabular}{ccc}
\hline Kwadran 3 & Kecepatan $(\mathrm{m} /$ det $)$ & Arah $\left(^{\circ}\right)$ \\
\hline Stasiun 11 & 0,139 & $80^{\circ}$ \\
Stasiun 12 & 0,444 & $80^{\circ}$ \\
Stasiun 13 & 0,389 & $75^{\circ}$ \\
Stasiun 14 & 0,278 & $80^{\circ}$ \\
Stasiun 15 & 0,333 & $75^{0}$ \\
Stasiun 16 & 0,333 & $80^{\circ}$ \\
Stasiun 17 & 0,417 & $75^{0}$ \\
\hline
\end{tabular}

Tabel 10 Kecepatan arus buoy pelacak pada posisi yang berdekatan dengan stasiun-stasiun di kwadran 4

\begin{tabular}{ccc}
\hline Kwadran 4 & Kecepatan $(\mathrm{m} /$ det $)$ & Arah $\left(^{\circ}\right)$ \\
\hline Stasiun 18 & 0,750 & $225^{0}$ \\
Stasiun 19 & 0,278 & $230^{0}$ \\
Stasiun 20 & 0,167 & $235^{\circ}$ \\
Stasiun 21 & 0,306 & $240^{\circ}$ \\
Stasiun 22 & 0,306 & $65^{\circ}$ \\
Stasiun 23 & 0,333 & $60^{\circ}$ \\
\hline
\end{tabular}

Kecepatan arus yang diperoleh baik dari buoy pelacak maupun pengukuran langsung menggunakan current meter terdapat perbedaan, sehingga untuk mendapatkan kecepatan arus yang lebih mendekati dan sesuai alat standar dapat dilakukan dengan meregresikan kedua nilai kecepatan tersebut. Hasil regresi sederhana kedua kecepatan tersebut diperlihat pada gambar berikut ini. 


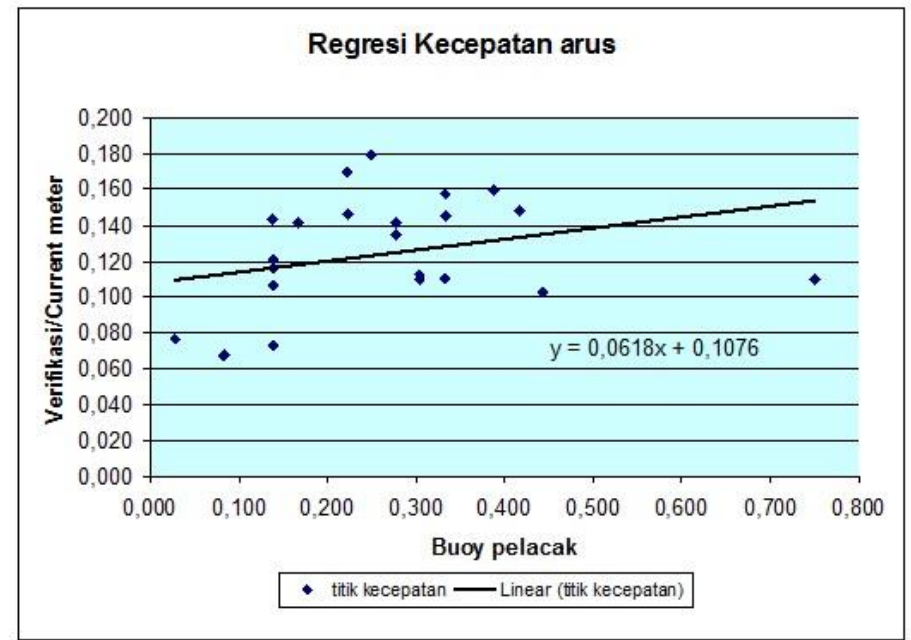

Gambar 11 Grafik Regresi kecepatan arus

\section{KESIMPULAN}

Desain dan konstruksi pelampung pelacak arus permukaan di perairan semi tertutup dapat berfungi sesuai dengan yang direncanakan, dari perhitungan regresi sederhana dari kedua kecepatan didapat persamaan $y=0,0618 x+0,1076$, dari persamaan tersebut dapat disimpulkan bahwa setiap kecepatan yang diproleh dari buoy pelacak dikalikan 0,0618 untuk mmendapatkan kecepatan yang lebih mendekati sebenarnya.

\section{DAFTAR PUSTAKA}

, Drift Study, 2003. Cobscook Bay Resource Center. http://www.cobscook.org

, Error Source, Defferential Correction, Accuration level, Terrasync Setting that effect accuration of GPS. http://www.montana.edu/ires357/place/gps/slide/gpsaccuracy.ppt

Abidin, H. Z. 1995. Penentuan posisi dengan GPS dan aplikasinya. Pradnya Paramita, Jakarta. 110 hal.

Abidin, H. Z., A. Jones dan J. Kahar. 1995. Survai dengan GPS. Cetakan 1 Pradnya Paramita. Jakarta. 154 hal.

Ackroyd, N. and Robert Lorimer. 1994. Global Navigation A GPS Use'r Guide. Second Edition Lloyd's of London Press Ltd. 197 pages.

Borden J., Shaumeyer J., Paul W., Irish J., Mollo-Christenseb E,. Provost D. 1997. Development of an Advanced Data Buoy Supporting MTPE Program. Presented at Technology 2000 : Enviromental Technologies Session IV, Boston, ast, 23 September 1997. http://bearcastel.com/wavic/pubs/pubs.php

Burwell D., 1997. Drifter Test of a Preliminary Version of the Trajectory Model.Tampa Bay,1997. http://www.onpl.marine.usf.edu/PORTS/drifter.html

Easton, R.L. 1980. “ The Navigation Technology Program “. In Global Positioning System. Papers published in Navigation, Volume I. Reprinted by the Institute of Navigation, Washington, D.C. pp. $15-20$ 
Hickey B., Kachel N., MacFadyen A., Adams N., Cochlan W., Connell L., Lessard E., Trainer V., Trick C., Wells M. 2003. ECOHAB PNW 1 CRUISE REPORTR/VwecomaW0306A June 2-23, 2003. http://www.ecohab.paw.org/w.0306a/report/

Hutabarat S, dan Stewat M. Evans. 1985. Pengantar Oseanografi. Cetakan Ke -2 UI-Press, Jakarta.

Krakiwsky, E.J. and D.E. Wells. 1971. Coordinate System in Geodesy. Departement of Surveying Eng. Univ of New Burnswick. Canada.

Lindsay, R. W. and H. Stern. 2002. The RadarSat Geophysical Processor System: Quality of Sea Ice Trajectory and Deformation Estimates, J. Atmos. and Ocean Tech., in press.

Sybrandy, A. L. and P. Niiler, 1991. WOCE/TOGA Lagrangian Drifter Construction Manual. WOCE Report No. 63; SIO Report No. 91/6. Scripps Institution of Oceanography, La Jolla, CA http://gpsdrifters/preliminary results/1-30-97.htm

Well, D.E. 1992. GPS positioning. Dept. of Surveying Engineering. University of Brunswick. Canada.

Well, D.E., N. Beck and, D. Delikaraoglou, A. Kleusberg, E.J. Krakiwsky, G. Lachapelle, R.B. Langley, M. Nakiboglu, K.P. Schwarz, J.M. Tranquilla, P. Vanicek 1986." Guide to GPS Positioning". Canadian GPS Associates. Fredericton, N.B., Canada. 